\title{
Erratum zu: Aufgaben zu Technische Mechanik 1-3
}

\section{Werner Hauger, Christian Krempaszky, Wolfgang A. Wall und Ewald Werner}

\section{Erratum zu:}

(C) Springer-Verlag GmbH Deutschland, ein Teil von Springer Nature 2020

W. Hauger et al., Aufgaben zu Technische Mechanik 1-3, https://doi.org/10.1007/978-3-662-61301-6

Auf Seite II wurde der akademische Titel von Prof. Dr. Ewald Werner korrigiert:

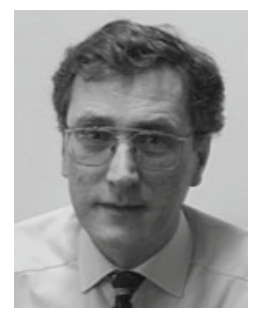

Prof. Dr. mont. DDr. h.c. Ewald Werner studierte Werkstoffwissenschaften, promovierte und habilitierte an der Montanuniversität Leoben. Er forschte am Erich Schmid Institut für Festkörperphysik der österreichischen Akademie der Wissenschaften und an der ETH Zürich. Von 1997 bis 2002 war er Professor für Mechanik an der TU München, seit 2002 leitet er dort den Lehrstuhl für Werkstoffkunde und Werkstoffmechanik. Seine Arbeitsgebiete sind die Metallphysik und die Werkstoffmechanik. Er ist Koautor von Lehrbüchern und Mitherausgeber mehrerer internationaler Fachzeitschriften.

Auf Seite IV wurde die Affiliation von PD Dr.-Ing. Christian Krempaszky korrigiert:

Christian Krempaszky

Technische Universität München

Garching, Deutschland

Auf Seite IV wurde das Copyright-Jahr der vorhergehenden Edition korrigiert:

Springer Vieweg

(C) Springer-Verlag GmbH Deutschland, ein Teil von Springer Nature 1991, 1994, 2001, 2005, 2006, 2008, 2012, 2014, 2017, 2020

Die aktualisierte Version der Titeleiseiten dieses Buches finden Sie unter

https://doi.org/10.1007/978-3-662-61301-6 


\section{Auf Seite IV wurde der Markenrechtstext korrigiert:}

Die Wiedergabe von allgemein beschreibenden Bezeichnungen, Marken, Unternehmensnamen etc. in diesem Werk bedeutet nicht, dass diese frei durch jedermann benutzt werden dürfen. Die Berechtigung zur Benutzung unterliegt, auch ohne gesonderten Hinweis hierzu, den Regeln des Markenrechts. Die Rechte des jeweiligen Zeicheninhabers sind zu beachten. 